\title{
Envisioning Eco-scapes for Healthy Urban Environments: A future to indemnify the past through passive measures
}

Saisha MATTOO, India

\begin{abstract}
As India inches closer every year towards becoming the world top ranker of economic development, the country continues to decline in human development. Diseases have crept into people's lives along with deteriorated ecological environments triggered by rapid industrialization and modernity. The economic impetus has taken a toll on people's wellness. Despite resources such as hospitals and clinics becoming easily accessible across the population, illnesses stay on a rise. This is because while these human-centric approaches ensure a cure, the very urban environment which causes them is not addressed. Today, the interaction between the two entities, that is human and environment ensures a very grim future for India. Not limited to addressing today's health and ecological concerns, Healthy Cities shall be a way of living for the Indian population. This cohesive understanding of individual, community and environment to understand and make more-than-human Healthy Urban Environments is exactly what the Indian cities have the potential to exhibit.
\end{abstract}

\section{Keywords}

Physical Health, Ecological Health, Healthy Urban Environment

\section{Introduction}

India has come a long way to hold the competitive place that it is crowned today, surpassing countries like the United Kingdom and France in the World Ranking of GDP. The role played by industrialization foremost to achieve this status is an implicit one. Increased labour and changing socio-economic patterns were part and parcel of the 'modern' boom in a technocratic sense, which can be traced back to the 18th century. The creation of 'modern' cities has been a fast process since then. Learning from our Western counterparts, Indian cities mimicked the American standards of planning leading to positive neighbourhoods, but in the long run the creation of what can be termed as Unhealthy Cities.

\section{Health and Neighbourhoods}

\subsection{Past Connections}

The connection between health and urbanism goes back almost as long as cities themselves. It was health concerns in many industrial-era cities that brought about visions such as the Garden city and Regional city models by Ebenezer Howard and Patrick Geddes respectively. The focus on health in city planning in India can be dated back to 1956. The Jaundice epidemic in the city of Delhi led to call for an investigation into Delhi's urban condition. The Ministry of Health with the Town planning Organization created the Interim 
General Plan for Greater Delhi ${ }^{1}$. A U.S.A-read team of planners, headed by Albert Meyers, planned neighbourhoods such as Vijay Nagar, Lajpat Nagar, Defence Colony, Patel Nagar, for the large influx of refugees post-partition, based on standards borrowed from the U.S.A. The city was broken up into various planning divisions, as well as cellular neighbourhoods: sub-centres, and district centres, to contain social life, commerce and work much like exclusive function based zones. The influence of American planning ideology is seen today in the garden-concept plans of Jangpura and Nizamuddin in Delhi. This concept was further copied across the Nation, assuming its successful immediate mitigation of the challenges being faced, the future impacts of which were unfathomable at the time. This was followed by dictating mandates for certain resources such as, drainage and sanitation, forest conservation, Coastal Zone Regulations which intended to curb the ongoing depletion of resources due to development.

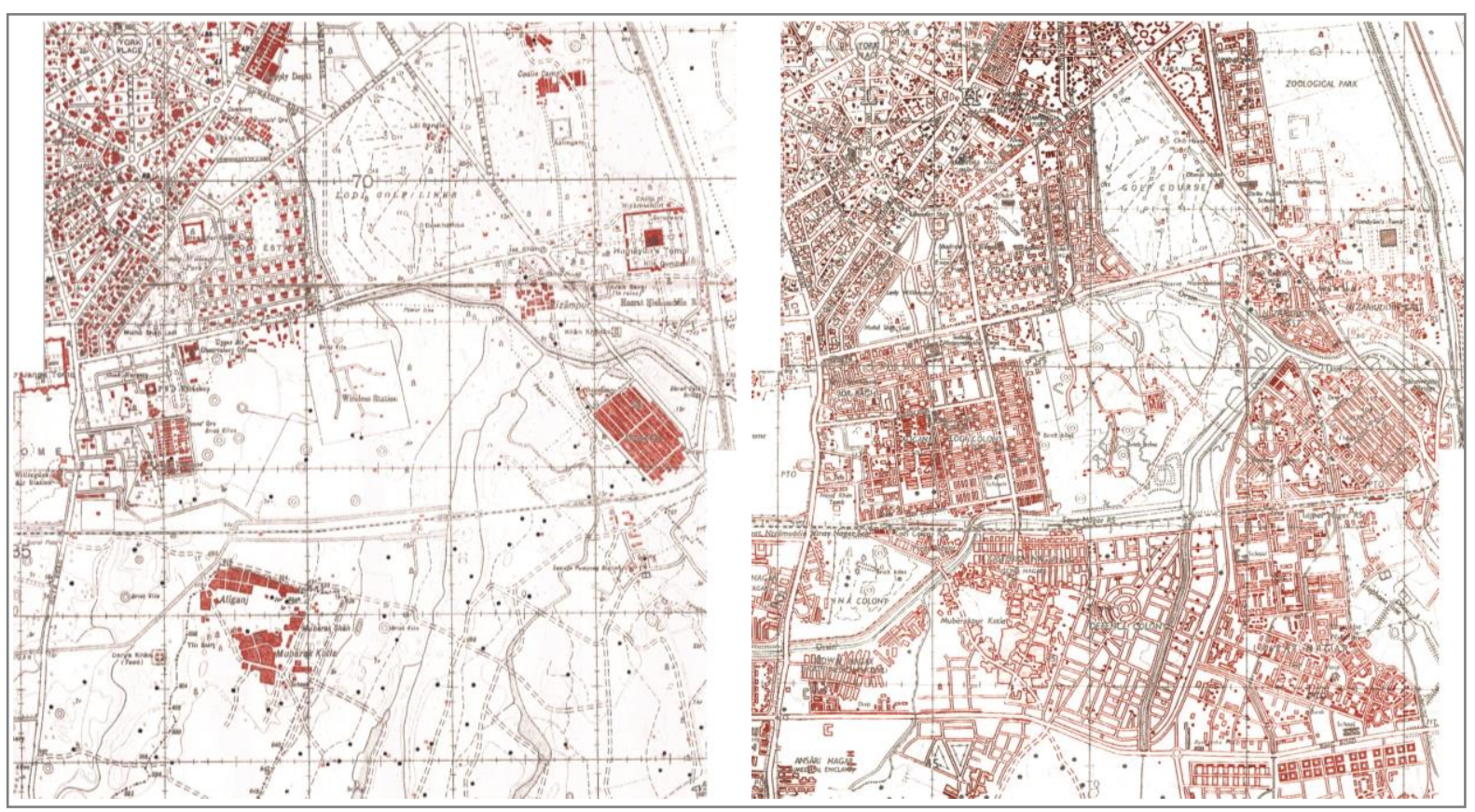

Figure 1. Map of area to the west of Humayun's Tomb in 1942(left) and 1956(right). Source: Alluri and Bhatia

This top-down approach of creating uniformly planned neighbourhoods in terms of infrastructure and morphology neglected the non-uniform contexts they were imposed on, which forced both socioeconomical parity, as well as natural resource deterioration. Construction of physical connections between these zones cut across the previously green spaces decimated the identity of the city to humans and their built environment, rivers were re-routed as required for developmental needs, forests were cut unchecked, and the city continued to expand radially reducing the agricultural buffer, known as Green Belt ${ }^{2}$, to a mere one village thick today. The deleterious environments created due to these developments, as an initiative of economic impetus, has had disastrous impacts on the physical, physiological and mental health of people. The urbane life of city residents, decorated with all its amenities, is tainted by these diseases and illness. Ranging from lifestyle diseases, such as obesity, diabetes, hypertension, to water and food-related, such as Typhoid, Anaemia, Food poisoning, Diarrhoea, as well as vector-borne such as Malaria and Dengue, formed the top causes of deaths in India in 2017 all

\footnotetext{
1 The Interim General Plan for Greater Delhi, made in 1956, was to check the tide of unplanned growth and settlement until the Master Plan itself was ready. The recommendations although based on estimated intuitions due to lack of actual figures and surveys were very close to the calculated suggestions of 1962 Master Plan.

${ }^{2}$ As per Master Plan Delhi 2021, Green Belt is an area which is kept and reserved for agricultural practice to ensure that there is open space and few activities are permissible in that area. It was first mentioned in the first Master Plan of Delhi 1962, directing a one mile thick buffer between Delhi's planned development and all neighbouring states.
} 
of which have seen an increase in percentage since 2007 (Institute for Health Metrics and Evaluation, 2017).

Despite health sector reforms that were undertaken as part of the Eleventh Five year Plan $^{3}$ by increasing public health and health care expenditures, the country ranks $145^{\text {th }}$ among 195 countries in terms of quality and accessibility of healthcare, according to the Global Burden of Disease 2017. The country lags behind China (48), Sri Lanka (71), Bangladesh (133) and Bhutan (134). Another evaluation ranks India on $3^{\text {rd }}$ and $1^{\text {st }}$ position globally for the percentage of Diabetic population and annual death rate due to Type 2 Diabetes respectively (Institute of Health Metrics and Evaluation, 2019). Similar physical and physiological health conditions have crept into the lives of urban residents across the globe, which is a matter of concern. The capital city, for example, comprising of planned and unplanned neighbourhoods of diverse socio-economic groups of population face health challenges, such as Hypertension, Obesity, Typhoid which have led to maximum annual deaths(State of Health of Delhi 2019). The COVID 19 pandemic is another example of how cities could not control the rampant spread of a communicable disease in the urban scenario. Road accident fatalities, although not a subset of disease and illness, is another form of effect the physical environment has on city residents, leading to 16 deaths per hour (IIHMR 2017).

\subsection{Pressing Concern of Contemporary times}

The question then arises as to why human development was not in tandem with economic development? Today, health in India is a matter of access to hospitals, nursing centres, mohalla clinics ${ }^{4}$, which collectively form the active built resources providing curative (cure based health) facilities to people. While they form the second most important need, in Maslow's Hierarchy pyramid, it is the elements of the primary slab, Physiological needs ${ }^{5}$, which need to be taken into concern. Despite meeting the detailed Master Plan standards for health infrastructure, Indian cities represent a deterioration of Physical Health ${ }^{6}$ of individuals, Social Health ${ }^{7}$ of community and Ecological Health ${ }^{8}$ of the city. This is because while these human-centric approaches ensure a cure, the very urban environment which causes them is not addressed. Passive stressors on people have led to this accelerating number of health issues, which have gone unchecked till now. The top factors contributing to the before-mentioned diseases and health problems include malnutrition and dietary risks, addictions such as alcohol and tobacco abuse, high blood pressure and sugar levels, high BMI, and compromised $\mathrm{WaSH}^{9}$. This further strengthens the arguments of health degradation due to a lack of nutritional requirements and physical activity, inappropriate lifestyle choices, and compromised hygiene.

Today, the interaction between the two entities, that is human and environment ensures a very grim future for India. With dying rivers, swelling garbage dumps, unchecked toxic infiltration in air and water, on one hand, an increased number of roads and flyovers, unchecked consumerism, industrial empire expansions, on the other hand, paints a daunting picture of tomorrow. The human hegemony over natural resources has and is continuing to take a toll on all biological life, humans included. The

\footnotetext{
3 The objective of the Eleventh Five Year Plan of India, approved in December 2007, was to improve quality of life for the citizens of the state and contribute to the larger national goals of socio-economic development. This required faster and more equitable social and economic development of the state.

${ }^{4}$ Aam Aadmi Mohalla Clinics (AAMC), also known as Mohalla Clinics, are primary health centres in Delhi in India, that offer a basic package of essential health services including medicines, diagnostics, and consultation free of cost. Mohalla in Hindi means neighborhood or community.

${ }^{5}$ Physiological needs are biological requirements for human survival, e.g. air, food, drink, shelter, clothing, warmth, sex, sleep which are considered the most important as all the other needs become secondary until these needs are met, according to Abraham Maslow.

${ }^{6}$ Physical health is defined as the condition of the body, taking into consideration everything from the absence of disease to fitness level (EUPATI).

${ }^{7}$ Social health is defined as the ability to form meaningful relationships with other people and interact in healthy, positive ways. The way people connect to other people around, adapt to different social situations, and experience a sense of belonging all contribute to social health.

8 The term Ecological Health has been used not only in terms of medicine and environment, but also human health. In urban design/planning terms, it refers to the quality of green content of the city, while in environmental terms it refers to the health of ecological system all together. While both these concepts are taken into consideration, the thesis leads to understand the effect of ecology on health of public, as well as the effect of public on the health of ecology.

${ }^{9} \mathrm{WaSH}$ is the collective term for Water, Sanitation and Hygiene. Universal, affordable and sustainable access to WASH is a key public health issue within international development and is the focus of the first two targets of Sustainable Development Goal 6.
} 
current greed to control and manipulate the environment for personal comfort shall have irreversible impacts which the future generations shall have to bear.

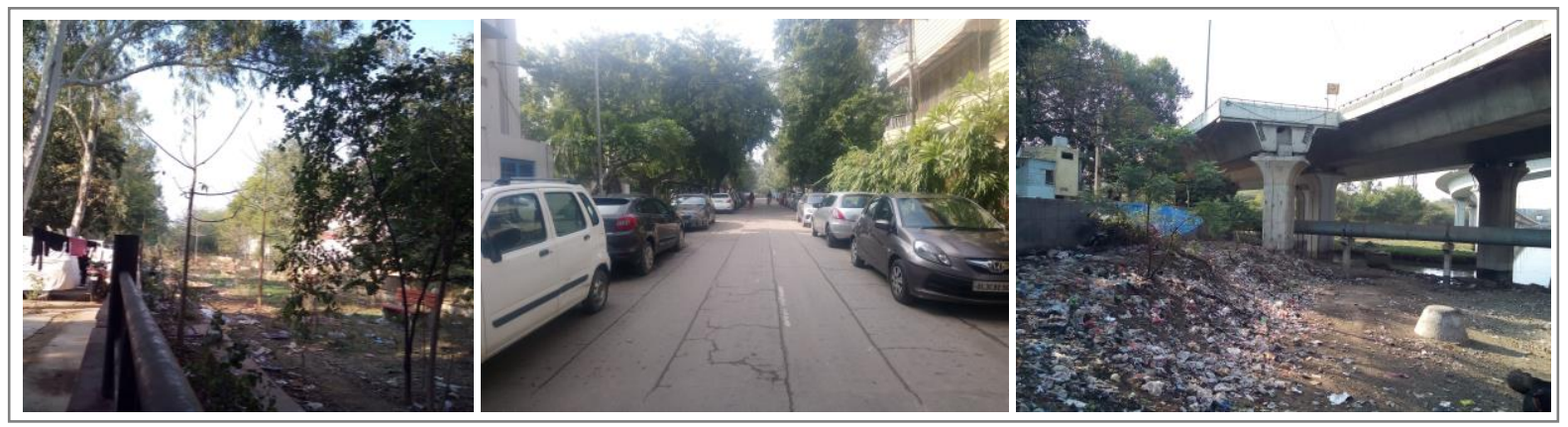

Figure 2. (From left to right) Central Park in Bhogal, a middle income residential neighbourhood in Delhi; Typical Street in Nizamuddin East, a high income residential neighbourhood in Delhi; Banks of Barapullah Nallah, a stream of Yamuna, at Jangpura, Delhi. Source: Author

The research on Urban Environments and its impact on Public Health has gained momentum globally in recent times, with legislative bodies taking in consultation from ecologists, urban and transport planners, sociologists and other related experts, to make manuals and standards, applicable on different scales. Envisioning the future from an optimist lens, Indian cities have the potential to ensure healthy environments to one and all. The planning fraternity having taken leaps in the past to ensure better liveable built spaces through regulations on Floor Area, and Ground coverage at the building level, ranging to the creation of drainage plans, sewage disposal models, forest regulations being a few on the city and national scale. The design fraternity correspondingly has been able to adapt strategies which have had local and regional impacts, starting from something as spot based as a street corner design, to cycle paths covering an entire city, such as Pune. While these approaches are still human-centric, feats are being achieved by landscape designers and environmental planners through visions of sustainable futures, focussing on Ecological Health. The environment has a major role to play in the health of people, which includes both the contextual built environment, as well as the unbuilt ecological scapes, thus shifting focus away from humans, but rather concentrating on the interactions of humans with cityscapes.

\section{Theoretical Concepts}

\subsection{Literature on Healthy Eco-scapes}

Cecily Maller defines Healthy Urban Environments as "places that acknowledge, invite and actively encourage some living non-humans to flourish, and where humans and non-humans can productively coexist and overall benefit from each other's presence". This cohesive understanding of individual, community and environment to understand and make more-than-human Healthy Urban Environments is exactly what the Indian cities have the potential to exhibit. Learning from the present, to visualise a future where one should not have to go through the same challenges as today, has been the impetus of visions and concepts. The gimmicks of the technocratic world have an impact only as long as there are no iterations, which makes dependence on such short-lived resources ungainly. For a future vision, as grounded as Healthy Urban Environments, which is not the creation of an ideal whole but health through parts, that is through human-environment interactions, cities through planning and design techniques shall be able to bring the ecological experience to people. Exposure to the environment has both physical and psychological impacts, which by and large are passive ways to enable the health of both humans and the environment consequently. 
The book 'Urban Sprawl and Public Health' written by Dr. Howard Frumkin, and co-authored by Lawrence Frank and Richard Jackson, advocates for a holistic view of urban design that considers health, the environment, social relations, political processes and the economy as part of the development process. It posits that neighbourhood design elements including land use, design character, transportation systems, sustainability, and density impact a neighbourhood's health, environment and quality of life. The author states "Community design and building design have impacts both on mental health and on social capital. Social capital in turn is a very important determinant of overall health." With a very similar focus, the Urban Land Institute suggests Healthy Places to be "designed, built, and programmed to support the physical, mental, and social well-being of the people who live, work, learn, and visit there. Healthy places (i) offer healthy and affordable housing options, and a variety of safe, comfortable, and convenient transportation choices, (ii) provide access to healthy foods, the natural environment, and other amenities that allow people to reach their full potential, (iii) are designed thoughtfully, to make the healthy choice the easy choice, and they are built using health-promoting materials, and (iv) address unique community issues with innovative and sustainable solutions."

The psychological impact of cities planned as Healthy Urban Environments is another important factor to understand. These neo-public spaces, envisioned through green and blue networks of the city are not only points of physical relief, but also urban happiness. These spaces as well the Healthy Environment lifestyle as a whole has the potential to become relief zones conducive to healing. With very little proven scientific research in this area, but the observations of behaviour counsellors and anthropological professional place ecological exposure to be of value for peace and calm of a generally active mind, thus enabling people with space and time to reflect and introspect.

\subsection{Investigable Gaps}

The literature about health and healthy urban environments does justify the non-avoidable dependence of public health on the built and unbuilt context that surrounds them. Both Cecily Maller, and Dr. Howard Frumkin has emphasized through their respective books the need to re-look at health and the factors which affect them, thus encouraging for preventive measures, rather than the much followed curative measure applied by the government through the provision of adequate health centres. Hierarchical allocation of health infrastructure has increased access to these institutions across all economic groups, thus making it an inclusive effort of reducing fatalities, but the possibility of preventing illness and diseases itself is still an unexplored realm in India. Place-making with a concentration on impacts on resident's health, as well as the reverse impact of the community and individuals on the physical and social structure of a place plays an important role in the creation of healthy liveable spaces.

An unexplored field in this context is the relationship between economic groups and their illness. While it has already been established that context has a role to play in health, there is a possibility to take this one step further to understand the people who house in that context. The disparity between economic groups housing in clusters of a local area becomes evident also in the morphological setting of the place. For example, the character of physical space inhabited by the economically weaker section of the society comprises of narrow street widths, less or negligible green space, conflict zones due to overlapping movement networks, poor sanitation facility, which leads to illnesses such as food poisoning, diarrhoea, water vector-borne diseases, the quick spread of communicable diseases etc. While one may assume that absence of such conditions in areas inhabited by the higher income group should mean the absence of diseases, that is not the case. The latter mentioned areas are zones of high vehicular movement, with minimum or no inclination to walk or cycle, thus leading to lifestyle diseases, such as hypertension, cardiovascular problems etc. Affordability of resources and basic facilities such as food also is another aspect, the dearth of which leads to anaemia among the poor section and excess of which (unhealthy food) to obesity amongst the high-income group.

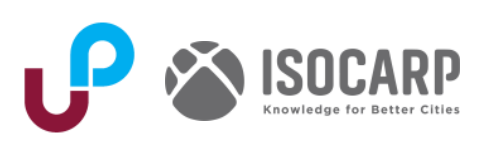


The role of governance has also not been explored concerning health yet. Policies and rules laid out by the planning institutions at the city level are an outcome of consideration and reference to western standards as well as the Indian context. While such restrictions and guidelines are in place, it is the implementation which brings changes in the scenario. For example, public open spaces constituting of neighbourhood and cluster parks, the edge of the green spaces with private properties and the road, should be accessible to one and all, justifying its public use, but whose spaces are these to intervene and change positively to ward off illness becomes a question of claim on the in-between area that no institution/organization seems to take.

\section{Urban Designer's Role}

Not limited to addressing today's health and ecological concerns, Healthy Cities ${ }^{10}$ shall be a way of living for the Indian population. Respecting the blue and green resources which surround us, as well as treating them equal to human life is the ideal way of approaching this vision. This vision requires steps at various scales of the city, with a constant concern towards overall human development. Neighbourhoods and cities provide with possibilities of health upliftment through the realization of impacts of movement, built-unbuilt character, activity anchors etc. on everyday lives of people. Potentials of urban design interventions are a product of disabling passive restrictions, thus mitigating the negative impacts of urban life as well as attaching a positive value to neutral resources, thus creating a wholesome healthy experience for the urban residents. These potentials are realised in all three spheres of life, the first place meaning residential neighbourhoods, working centres that is the second place and recreation areas which make the third place.

The city plans neighbourhoods and various resources required at multiple scales to cater to them. The market force when works on these resources, some zones due to morphological or economic factors become redundant, which leads to inactive spaces. Existing city resources, such as the neighbourhood community centres which lie under-utilized due to restricted access or lack of contextual activity generators, have the potential to re-engage the residents in the public sphere, enabling physical, social and ecological health. Similarly, infrastructural voids, such as the ground zone of flyovers which prove to be unsafe spaces due to lack of character, can through Urban Design process inculcate activity anchors, with an overarching intent to enable public activity.

Another example of eco-space curation is realizing the potential of zones which have with time degraded to negative spaces, such as a nallah ${ }^{11}$, which across most of urban India has degraded to an unhealthy, garbage-filled water network. The re-purposefulness of these neutral or negatively affecting spaces adds positive values to become a part of the daily activity cycle. With smaller socio-spatial steps, such as the promotion of Urban Forestry, and Urban Agriculture instead of unwanted ghats ${ }^{12}$, along deteriorating inaccessible river beds, shall have implications such as better air quality, balanced river ecosystem, organic produce availability at cheaper prices for the lower section of society reducing anaemia and food poisoning, as well as encouraging healthier snack options for the higher income groups, reducing obesity.

The inter-neighbourhood and city edges play a vital role in the everyday life of people. They can restrict or allow through movement and access with respect to the character of the edge, while the function of the edge defines the predominant activity or inactivity generated. While restricted access does not directly cause any illness or disease, and is thus not actively responsible in health deterioration, but this neutral aspect has the potential to be turned into a positive health contributor. The edges can be

\footnotetext{
10 According to the WHO Health Promotion Glossary 1998, a 'Healthy City' is one that is continually creating and improving those physical and social environments and expanding those community resources which enable people to mutually support each other in performing all the functions of life and developing to their maximum potential.

11 Nallah: stream or watercourse

${ }^{12}$ Ghat: a flight of steps leading down to a river
} 
seen as potential seams between zones of varying character, thus enabling greater physical and visual porosity to points of interest. One example is a single entry point access to a park from a fast-paced vehicular corridor. The linear park may show potential to be accessed from multiple points, for direct movement across neighbourhoods, which will require breaking the monotony of the grilled seam of the park. Re-imagining green spaces as both go-to and go-through spaces create opportunities for safe pedestrian connections across different service anchors of the city, which shall enable walking and cycling and thus an active lifestyle.

\section{Conclusion}

The present, although bleak, has the potential to re-emerge brighter with Indian cities progressing from the 'developing' status to the 'developed' status, with a focus on overall development. Within two decades India has been able to increase its $\mathrm{HDI}^{13}$ by approximately 0.2 points, standing at 0.64 in 2017 which makes this vision of enabling health in the modern cities achievable. Governance and multidisciplinary approach have a major role to play, as well as public participation which has been initiated in cities with many successful stories. With the strengthening of socio-ecological relationships, there is a wide range of challenges which can be overcome. The power to think for a better future gives great responsibility to create sustainable, healthy and thus liveable environments, a future which can be secured through a nuanced approach, strengthening the performativity of the individual and the community as a whole apart from the greener and bluer eco-scapes.

The need to focus on liveable and healthier environments has been advocated time and again by various specialists, though means to do so, as well as the role of multiple professionals, remains unclear. Herman Edward Daly, a famous American ecologist and Georgist economist wrote in For the Common Good: Redirecting the economy toward community, the environment, and a sustainable future:

"Even if we could grow our way out of the crisis and delay the inevitable and painful reconciliation of virtual and real wealth, there is the question of whether this would be a wise thing to do. Marginal costs of additional growth in rich countries, such as global warming, biodiversity loss and roadways choked with cars, now likely exceed marginal benefits of a little extra consumption. The result is that promoting further economic growth makes us poorer, not richer."

\footnotetext{
13 Human Development (HDI) is a summary measure of average achievement in key dimensions of human development: a long and healthy life, being knowledgeable and have a decent standard of living. It is the geometric mean of normalized indices for each of the three dimensions assessed by life expectancy at birth, mean of years of schooling for adults aged 25 years and more and expected years of schooling for children of school entering age, and gross national income per capita.
} 


\section{References}

Alluri, A. and Bhatia, G. (n.d.). The decade that changed Delhi. [online] https://www.hindustantimes.com/static/partition/delhi/?fbclid=IwAR19cV8GM3PMARWTSUGO ohknqfD68uRMtXZh2ISodG5Sp6Iz3tFsvbyqK3U. Available at: https://www.hindustantimes.com/static/partition/delhi/?fbclid=IwAR19cV8GM3PMARWTSUGO ohknqfD68uRMtXZh2ISodG5Sp6Iz3tFsvbyqK3U [Accessed 23 Aug. 2020].

Duhl, L. and Sanchez, A. (1999). HEALTHY CITIES AND THE CITY PLANNING PROCESS. [online] World Health Organization. Available at: https://www.euro.who.int/_data/assets/pdf_file/0009/101610/E67843.pdf [Accessed 18 Aug. 2020].

EUPATI. Physical health. [online] Available at: https://www.patientsacademy.eu/glossary/physicalhealth/ [Accessed 22 Aug. 2020].

Hancock, T. (1985). The mandala of health: a model of the human ecosystem. Family \& Community Health, [online] 8(3), pp.1-10. Available at: https://www.researchgate.net/publication/13024742_The_Mandala_of_Health_A_Model_of_th e_Human_Ecosystem [Accessed 27 Aug. 2020].

Healthdata.org. (2017). Global Burden of Disease Study 2017 (GBD 2017) Data Resources | GHDx. [online] Available at: http://ghdx.healthdata.org/gbd-2017 [Accessed 23 Dec. 2019].

Healthy Cities. (2019). World Health Organization. [online] Available at: https://www.who.int/healthpromotion/healthy-cities/en/ [Accessed 23 Dec. 2019].

“Healthy Cities Vision." Who.Int, 23 Dec. 2019, www.euro.who.int/en/health-topics/environment-andhealth/urban-health/who-european-healthy-cities-network/healthy-cities-vision, http://www.euro.who.int/en/health-topics/environment-and-health/urban-health/whoeuropean-healthy-cities-network/healthy-cities-vision. Accessed 23 Dec. 2019.

IIHMR Delhi (2017). Urban Health- unique problems, need unique solutions. [online] Medium. Available at: https://medium.com/@iihmrdelhi/urban-health-unique-problems-need-unique-solutions35b0c8735b4 [Accessed 29 Dec. 2019].

Institute for Health Metrics and Evaluation. (2017). India. [online] Available at: http://www.healthdata.org/india.

Maller, C. (2020). HEALTHY URBAN ENVIRONMENTS : more-than-human theories. S.L.: Routledge.

Report on The STATE of HEALTH of DELHI. (2019). [online] PRAJA.org. Available at:http://www.praja.org/praja_docs/praja_downloads/Report\%20on\%20The\%20STATE\%20of\%2 OHEALTH\%20of\%20DELHI.pdf [Accessed 1 Jan. 2020].

Schettler, T. (n.d.). Toward an Ecological View of Health: An Imperative for the Twenty-First Century | The Center for Health Design. [online] www.healthdesign.org. Available at: https://www.healthdesign.org/chd/research/toward-ecological-view-health-imperative-twentyfirst-century [Accessed 22 Aug. 2020].

Urban Land Institute (2013). Intersections : health and the built environment. Washington Dc: Urban Land Institute.

Von Szombathely, M.; Albrecht, M.; Antanaskovic, D.; Augustin, J.; Augustin, M.; Bechtel, B.; Bürk, T.; Fischereit, J.; Grawe, D.; Hoffmann, P.; et al. A Conceptual Modeling Approach to Health-Related Urban Well-Being. Urban Sci. 2017, 1, 17. 